\title{
Reactive airways dysfunction syndrome from acute inhalation of dishwasher detergent powder
}

\author{
Timo J Hannu MD PhD², Vesa E Riihimäki MD PhD², Päivi L Piirilä MD PhD³
}

\begin{abstract}
TJ Hannu, VE Riihimäki, PL Piirilä. Reactive airways dysfunction syndrome from acute inhalation of dishwasher detergent powder. Can Respir J 2012;19(3):e25-e28.
\end{abstract}

Reactive airway dysfunction syndrome, a type of occupational asthma without a latency period, is induced by irritating vapour, fumes or smoke. The present report is the first to describe a case of reactive airway dysfunction syndrome caused by acute exposure to dishwater detergent containing sodium metasilicate and sodium dichloroisocyanurate. The diagnosis was based on exposure data, clinical symptoms and signs, as well as respiratory function tests. A 43-year-old nonatopic male apprentice cook developed respiratory symptoms immediately after exposure to a cloud of detergent powder that was made airborne by vigorous shaking of the package. In spirometry, combined obstructive and restrictive ventilatory impairment developed, and the histamine challenge test revealed bronchial hyperresponsiveness. Even routine handling of a strongly caustic detergent, such as filling a dishwasher container, is not entirely risk free and should be performed with caution.

Key Words: Cleansing; Occupational exposure; Occupational lung disease; Sodium dichloroisocyanurate; Sodium metasilicate

\section{Un syndrome de dysfonction réactive des voies aériennes causé par l'inhalation aiguë de détergent en poudre pour lave-vaisselle}

Le syndrome de dysfonction réactive des voies aériennes, un type d'asthme professionnel sans période de latence, est induit par des vapeurs, des émanations ou des fumées irritantes. Le présent rapport est le premier à décrire un syndrome de dysfonction réactive des voies aériennes causé par une exposition aiguë à un détergent pour lave-vaisselle contenant dumétasilicate de sodium et du dichloroisocyanurate de sodium. Le diagnostic se fondait sur les données d'exposition, les signes et symptômes cliniques et les tests de fonction respiratoire. Un apprenti cuisinier de 43 ans non atopique a présenté des symptômes respiratoires immédiatement après avoir été exposé à un nuage de poudre pour lave-vaisselle devenue aérogène après l'agitation vigoureuse de la boîte. En spirométrie, une atteinte ventilatoire obstructive et restrictive combinée s'est manifestée, et le test de provocation à l'histamine a révélé une hyperréactivité bronchique. Même la manipulation normale d'un détergent très caustique, comme remplir le contenant d'un lave-vaisselle, n'est pas complètement sans risque et doit être effectuée avec prudence.
$\mathrm{R}$ eactive airway dysfunction syndrome (RADS) is characterized by R the immediate onset of asthma that follows a single exposure to irritating vapour, fumes or smoke (1). More than 30 different substances have been associated with the onset of RADS (2).

It is well-known from paediatric practice that ingestion or inhalation of strongly alkaline laundry or dishwasher powders by toddlers may cause serious respiratory and esophageal injury (3). To our knowledge, this association has not been previously reported in an occupational setting. We present a case of RADS in an apprentice cook following acute inhalation of a strongly alkaline dishwasher detergent powder containing sodium metasilicate and sodium dichloroisocyanurate.

\section{CASE PRESENTATION}

The patient was a 43-year-old man who worked for 25 years as a carpet layer without exposure to known respiratory sensitizers. At the time of the incident, he was, because of nonrespiratory health problems, undergoing retraining to become a cook within a vocational rehabilitation program. His medical history revealed neither atopic dermatitis nor perennial rhinitis in his childhood. He was an occasional, sporadic smoker, at most smoking one pack in a week. Before the incident, he did not have any respiratory complaints.

During the incident, the patient was preparing to fill the detergent container of a large dishwasher in the institute kitchen. Because the detergent powder was lumpy, he shook the large package vigorously, which dispersed a cloud of fine dust. Inhalation of this dust induced immediate, intense coughing.
After the incident, the patient was taken without a delay to the emergency unit of a central hospital situated in the community. He still experienced cough but not dyspnea. Lung auscultation was normal and his peak expiratory flow rate was $380 \mathrm{~L} / \mathrm{min}$. A chest $\mathrm{x}$-ray was normal. He was treated with nebulized salbutamol and beclomethasone dipropionate $(4000 \mu \mathrm{g} /$ day $)$ aerosol inhalations. The cough subsided during the course of two days of observation in the hospital. Spirometry performed two days after the incident suggested mild obstruction based on a slightly decreased maximal expiratory flow of $50 \%$ of vital capacity (58\% of the predicted value) (4) (Table 1). At discharge, inhaled beclomethasone dipropionate medication $(2000 \mu \mathrm{g} /$ day in the first week, $1000 \mu \mathrm{g} /$ day thereafter) was continued with salbutamol inhalations on demand.

Spirometry examination was repeated one month after the incident, and a mild obstruction was now more obvious than in the first examination (Table 1). During his sick leave, the patient occasionally experienced dyspnea and was awakened at night because of it. Five to seven months after the incident, spirometry again showed mild obstruction without a significant bronchodilatation response, and a slight bronchial hyper-responsiveness was noted in a histamine challenge test $\left(\mathrm{PD}_{15} 0.857 \mathrm{mg}[5]\right)$ (Table 1). The patient continued to use inhaled beclomethasone dipropionate medication $(1000 \mu \mathrm{g} /$ day $)$ with salbutamol on demand. Sixteen months after the incident, he was still showing slight bronchial hyper-reactivity (Table 1). Because the patient did not find employment as a cook after the vocational rehabilitation, he returned to his former trade as a carpet layer approximately 18 months after the incident.

${ }^{1}$ Finnish Institute of Occupational Health, Occupational Medicine, Helsinki; ${ }^{2}$ Kalenteritie, Espoo; ${ }^{3}$ Helsinki University Central Hospital,

Laboratory of Clinical Physiology, Helsinki, Finland

Correspondence: Dr Timo Hannu, Finnish Institute of Occupational Health, Occupational Medicine, Topeliuksenkatu 41 a A,

FI-02500 Helsinki, Finland. Telephone 358-30-474-2575, fax 358-30-474-2149, e-mail timo.hannu@helsinki.fi 
TABLE 1

Results of spirometric examinations and bronchial hyper-responsiveness during follow-up

\begin{tabular}{|c|c|c|c|c|c|c|c|}
\hline Study period & $\begin{array}{c}\text { Time from incident, } \\
\text { months }\end{array}$ & $\begin{array}{c}\mathrm{FEV}_{1}, \mathrm{~L} / \mathrm{min} \\
\text { (\% predicted) }\end{array}$ & $\begin{array}{c}\text { FVC, } \mathrm{L} \\
\text { (\% predicted) }\end{array}$ & $\begin{array}{l}\text { Bronchodilation } \\
\text { response for } \mathrm{FEV}_{1}{ }^{*}\end{array}$ & $\begin{array}{c}\mathrm{FEV}_{1} / \mathrm{FVC} \\
(\% \text { predicted) }\end{array}$ & $\mathrm{MEF}_{50}, \mathrm{~L} / \mathrm{s}(\%)$ & $\mathrm{PD}_{15}, \mathrm{mg}$ \\
\hline \multirow[t]{4}{*}{ Sick leave } & 0.07 & $3.12(81)$ & $3.90(84)$ & $-3 \%$ & $80.03(96)$ & $3.12(58)$ & NM \\
\hline & 0.75 & $2.83(73)$ & $3.68(80)$ & $-1 \%$ & $76.81(92)$ & $2.58(48)$ & NM \\
\hline & 5 & $2.83(74)$ & $3.79(82)$ & $+3 \%$ & $74.53(90)$ & $2.61(49)$ & NM \\
\hline & 7 & $2.67(70)$ & NM & NM & NM & NM & 0.857 \\
\hline Rehabilitation & 15 & $2.73(71)$ & $3.87(84)$ & NM & $71(85)$ & $2.30(43)$ & NM \\
\hline Carpet layer & 65 & $2.47(66)$ & $3.52(78)$ & $+7 \%$ & $70.20(85)$ & NM & NM \\
\hline
\end{tabular}

Data presented as observed and as \% of the predicted value (4), unless otherwise indicated. ${ }^{*}$ Assessed as reported in reference 4 , limit of significance $\geq 12 \%$. FEV 1 Forced expiratory volume in $1 \mathrm{~s}$; FVC Forced vital capacity; MEF $F_{50}$ Maximal expiratory flow at the volume level of $50 \%$ of FVC; NM Not measured; $P D_{15}$ Provocative dose of histamine disulphate causing a reduction of at least $15 \%$ in FEV (bronchial hyper-responsiveness graded as $P D_{15}<0.1 \mathrm{mg}$ strong, $P D_{15} 0.1 \mathrm{mg}$ to $0.4 \mathrm{mg}$ moderate, $P D_{15} 0.4 \mathrm{mg}$ to $1.6 \mathrm{mg}$ slight, and $P D_{15}>1.6 \mathrm{mg}$ no hyper-reactivity (reference 5); $P E F$ Peak expiratory flow

Five years after the incident, the patient's insurance company retrospectively requested the Finnish Institute of Occupational Health (FIOH) to re-evaluate the patient's health status for the qualification process of an occupational accident. He continued to occasionally experience dyspnea and used salbutamol on demand, despite regular beclomethasone medication $(400 \mu \mathrm{g} /$ day $)$. At the $\mathrm{FIOH}$, spirometry continued to show mild obstruction. The diagnosis of RADS was made based on the following: acute inhalation of dishwasher detergent powder; the concurrent emergence of persistent respiratory symptoms; chronic occurrence of mild bronchial obstruction (both obstruction and restriction); and persistent bronchial hyper-reactivity in follow-up lung examinations (Table 1). After the examinations, the patient was advised to continue using inhaled, on-demand beclomethasone dipropionate medication with salbutamol on demand.

\section{DISCUSSION}

The criteria of RADS suggested by Brooks et al (1) are commonly used. These criteria include a documented absence of preceding respiratory complaints and onset of symptoms after a single specific exposure incident to an irritating gas, smoke, fumes or vapour present in very high concentrations. Furthermore, the onset of symptoms should occur within $24 \mathrm{~h}$ after the exposure and persist for at least three months, the symptoms should be consistent with asthma (cough, wheezing, chest tightness and dyspnea) and while pulmonary function tests might show airflow obstruction, methacholine challenge testing should be positive and other types of pulmonary disease should be ruled out. The obstructive lung disease in our patient fulfilled these criteria, except he developed a combined (both restrictive and obstructive) ventilatory impairment.

Cleaning agents are typically composed of active ingredients that depend on the technical function of the cleaning agent, additives and, usually, water (6). Active components include surfactants, complexing agents or water softeners, disinfectants, and acidic or alkaline substances. Alkaline agents dissolve calcium and fatty substances, improve the effect of surfactants by regulating the $\mathrm{pH}$ of the solution and inhibit the corrosion of metal surfaces (6). The dishwasher detergent that our patient was exposed to contained $\geq 30 \%$ of sodium metasilicate (CAS $6834-92-0)$ and $5 \%$ to $15 \%$ sodium dichloroisocyanurate dihydrate (CAS 51580-86-0).

Sodium metasilicate $\left(\mathrm{Na}_{2} \mathrm{SiO}_{3}\right)$ is a strong base - the $\mathrm{pH}$ of a $1 \%$ aqueous solution is approximately 13 (7). Therefore, it is a strong irritant and highly corrosive due to its high buffering capacity. Acute exposure involving inhalation of dusts may cause irritation of the respiratory tract and corrosive damage from contact with mucous membranes in the trachea and bronchi (7). Sodium dichloroisocyanurate is a disinfectant and oxidizer because it releases chlorine gas on reaction with water (8). It is moderately irritating to the eyes, upper respiratory tract and moist or abraded skin. In the literature, a case involving asthma in an ophthalmologist following exposure to sodium dichloroisocyanurate has been published (9). In that case, in which the chemical was being used for disinfection of tonometer heads, the exposure was not immediate but chronic, occurring intermittently over a six-year period.

In our patient, despite inhaled steroid medication, forced expiratory volume in $1 \mathrm{~s}\left(\mathrm{FEV}_{1}\right)$, forced vital capacity (FVC) and $\mathrm{FEV}_{1} / \mathrm{FVC}$ values were reduced during one month after the accidental inhalation of the irritating and corrosive cleaning agent. This suggests that an irreversible obstructive process developed, although results of lung function studies before the incident were not available. Compared with reference values, his lung function was gradually reduced, and a combined (both obstructive and restrictive) ventilatory function impairment gradually developed. High-dose, inhaled steroid medication was started during the acute phase, which may have diminished the development of respiratory symptoms. The continuous use of inhaled steroids may have contributed to the development of only slight ventilatory function impairment.

During rehabilitation and working as a carpet layer, exposure to irritants and inhaled solvents could not be excluded. Inhaled steroid medication was continued during the working period. However, the most important complaints during working were headache and musculoskeletal problems. Thus, it is not likely that irritants during rehabilitation or working would have influenced his ventilatory function.

\section{CONCLUSION}

A case of RADS induced by acute inhalation of dishwasher detergent containing sodium metasilicate and sodium dichloroisocyanurate is described for the first time. Typical for our patient was the development of combined (both restrictive and obstructive) ventilatory impairment, with persistent bronchial hyper-reactivity and asthmalike symptoms. The present case illustrates that careless handling of strongly alkaline detergent powders may constitute a hazard even for workers in addition to the well-recognized hazards for toddlers in the home.

\section{REFERENCES}

1. Brooks SM, Weiss MA, Bernstein IL. Reactive airways dysfunction syndrome (RADS). Persistent asthma syndrome after high level irritant exposures. Chest 1985;88:376-84.

2. Gautrin D, Bernstein IL, Brooks SM, Henneberger PK. Reactive airways dysfunction syndrome and irritant-induced asthma. In: Bernstein IL, Chan-Yeung M, Malo J-L, Bernstein DI, eds. Asthma in the workplace. New York: Taylor \& Francis, 2006:581-630.

3. Bertinelli A, Hamill J, Mahadevan M, Miles F. Serious injuries from dishwasher powder ingestions in small children. J Paediatr Child Care 2006;42:129-33. 
4. Viljanen AA. Reference values for spirometric, pulmonary diffusing capacity and body plethysmographic studies. Scand J Clin Invest 1982;42(Suppl 159):1-50.

5. Sovijärvi ARA, Malmberg LP, Reinikainen K, Rytilä P, Poppius H. A rapid dosimetric method with controlled tidal breathing for histamine challenge: Repeatability and distribution of bronchial reactivity in a clinical material. Chest 1993;104:164-70.

6. Wolkoff P, Schneider T, Kildes $\varnothing$ J, Degerth R, Jaroszewski M, Schunk H. Risk in cleaning: Chemical and physical exposure. Sci Total Environ 1998;215:135-56.
7. International Programme on Chemical Safety. Sodium metasilicate. <www.inchem.org/documents/pims/chemical/pim500.htm> (Accessed May, 2011).

8. Canadian Centre for Occupational Health and Safety. Sodium dichloroisocyanurate dihydrate. (Monograph) Canada, 1990.

9. Goverdhan S, Gaston H. Sanichlor-induced atopic dermatitis and asthma in ophthalmologists. Eye 2003;17:108-9. 


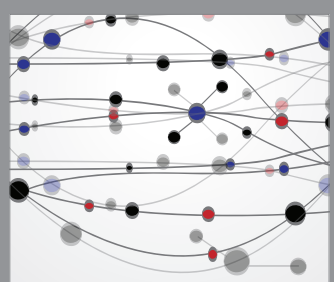

The Scientific World Journal
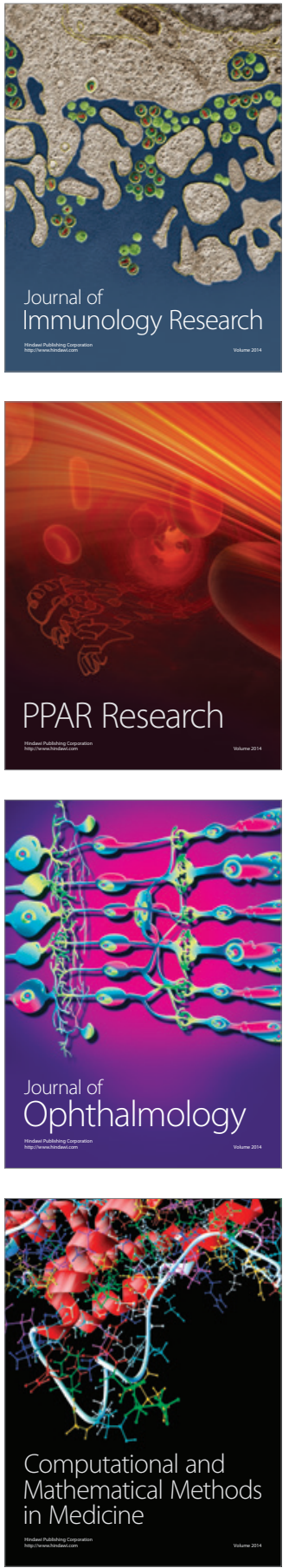

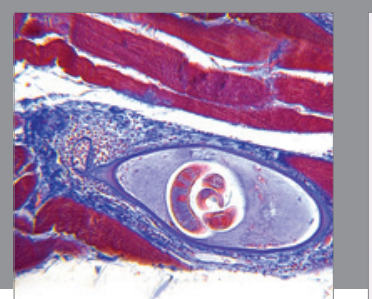

Gastroenterology Research and Practice

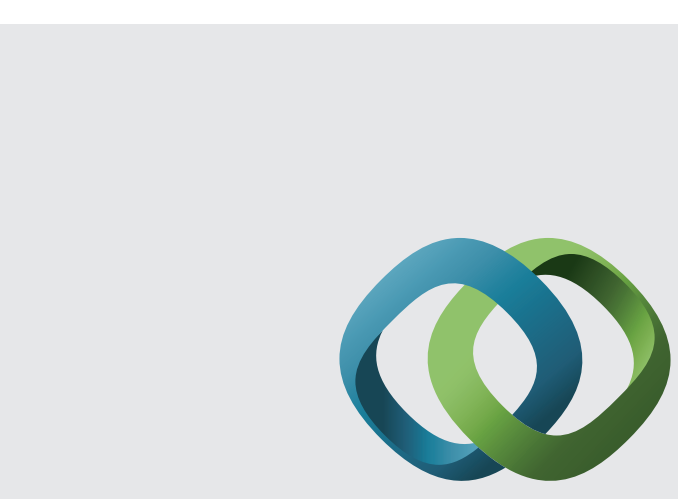

\section{Hindawi}

Submit your manuscripts at

http://www.hindawi.com
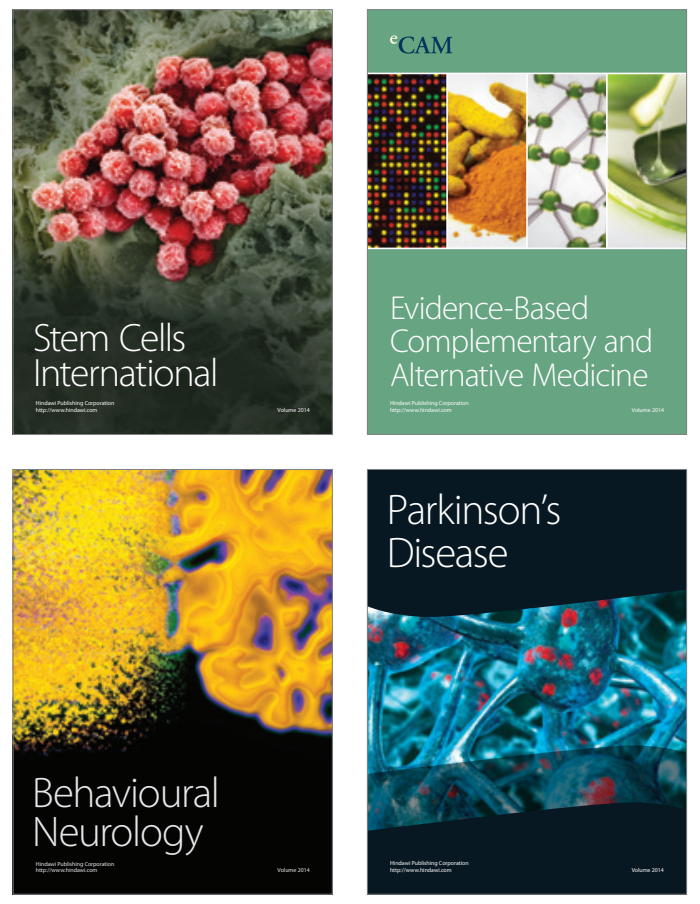
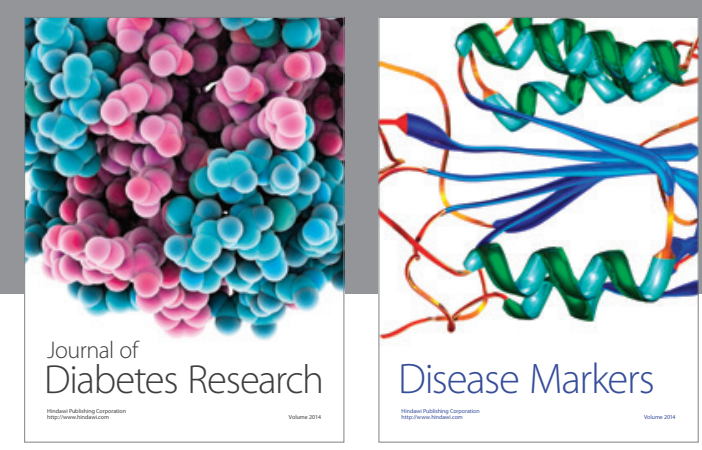

Disease Markers
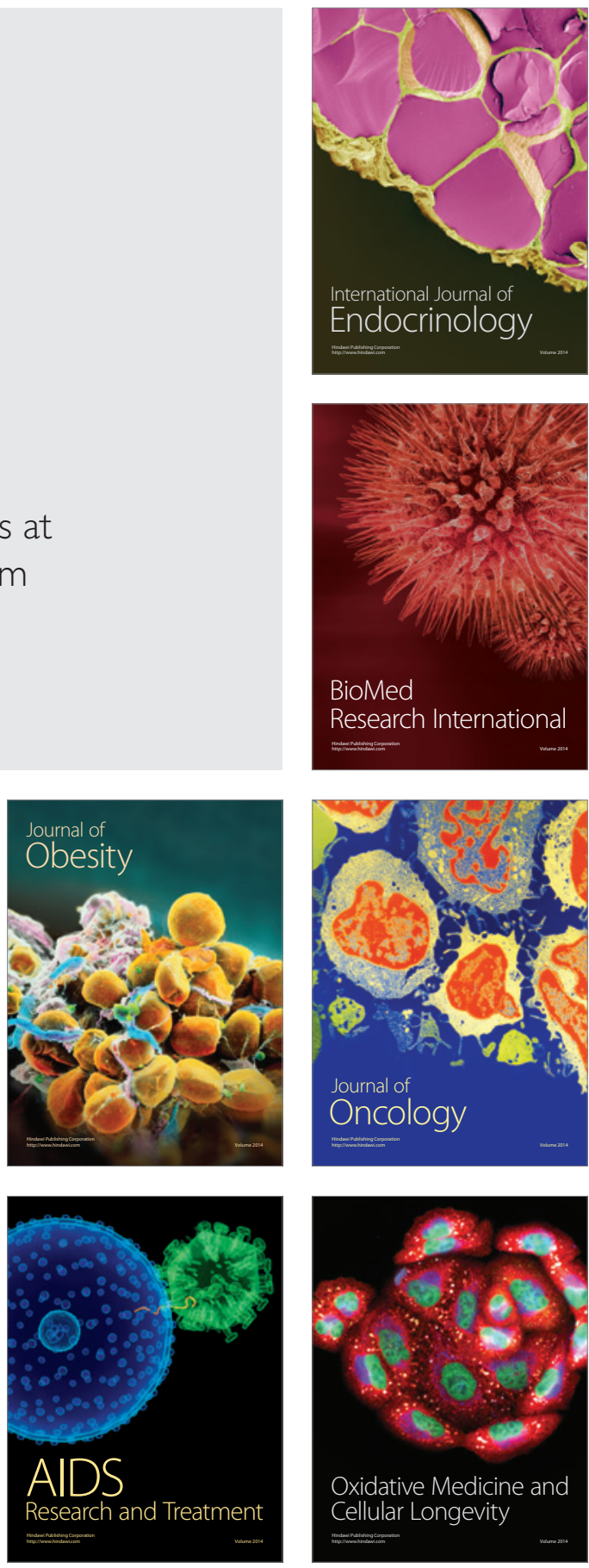